\title{
Therapy Used at Visit
}

National Cancer Institute

\section{Source}

National Cancer Institute. Therapy Used at Visit. NCI Thesaurus. Code C157517.

An indication of the type of therapy used during a visit. 